\title{
The Substitutability Between Discretionary and Contractual Saving and the 'Propensity' to Save Profit and Wage Income in the UK*
}

\author{
by Christos N. Pitelis**
}

\section{Introduction}

The aim of this paper is to test the substitution hypothesis of saving according to which household regard their contractual saving (e.g. pension funds and /or corporate retained earnings) as full substitutes for their personal discretionary saving. Also the related hypothesis that households save different proportions out of their profit and wage income. The estimated framework used is a saving function for the household sector which is shown to be sonsistent in its estimated form with most comsumption/saving models available today, Section 2 . In this framework we suggest a definition of the variables to be used, based on the idea that households take their consumption/saving decisions principally on the basis of their discretionary income; they do not take fully into account their contractual saving, pension funds and/or corporate retained earnings (CORE). This gives rise to an extended version of the estimated equation derived in Section 2, which becomes our estimated model, Section 3. In Section 4 we use annual UK time series data to test the hypotheses referred to above, in the framework of this model. Section 5 follows with concluding remarks.

\section{The estimated equation}

Among the various theories proposed to explain consumption/saving behavious those well known are: the Life Cycle Hypothesis (LCH) of Ando and Modigliani [1963], the Adaptive Expectations/Permanent Income Hypothesis primarily associated with Friedman [1957] and the Houthakker-Taylor (H-T) [1970] Hypothesis. Less elaborate but well known are also the Partial Adjustment and the Simple Lag/Habit Persistence Hypotheses of consumption, the latter originally advanced by Brown [1952].

Since long, the similarities and differences between these models in their estimated forms, assumed interest: as it is via estimation that the relative merits of the underlying hypotheses may be (dis)proved and discrimination achieved.

* Earlier versions of this paper have been presented to an Economic Theory Workshop at Warwick, and the European Association of Risk and Insurance Economists in Brussels, September 1985. To their participants I am grateful. For comments and discussion I am indebted to: K. Cowling, G.W. Dewit D. Kessler, D. Leech, K. Wallis and an anonymous referee of this Journal.

** Department of Industrial Economics, Accountancy and Insurance, University of Nottingham. 
An important result along these lines is Swamy [1968] who demonstrated the equivalence of the H-T model and the LCH. The result was acknowledged by Houthakker and Taylor [1970] and Modigliani [1975] but found little application in empirical research. The similarities on the other hand in the estimated forms of the Adaptive Expectations/Permanent Income, the Partial Adjustment and the Simple Lag/Habit Persistence hypotheses of consumption are very well documented by now, see e.g. Wallis [1979], Davis [1984] for expositions. In brief, they are all associated with the existence of a Lagged Dependent Variable (LDV) in their estimated equations. Spiro [1962] and more recently Davidson et al [1978] have also shown that the $\mathrm{LCH}$ can be brought in a form similar to these models. Consider e.g. the LCH as in Modigliani [1975]:

$$
C_{t}=\alpha Y_{t}+(\delta-r) W_{t}
$$

where $C_{t}$ denotes consumer expenditure in period $t$, and $Y_{t}$ and $W_{t}$ are appropriately defined income and wealth variables: $r$, is the rate of return on assets and $\alpha$ and $\delta$ are constants. Then from the definition

$$
W_{t}=W_{t-1}+Y_{t-1}-\mathrm{C}_{t-1}
$$

it follows that,

$$
\begin{aligned}
C_{t}=\alpha & Y_{t}+(\delta-r-\alpha) Y_{t-1} \\
& +(1-\delta+r) C_{t-1}
\end{aligned}
$$

where the LDV is again present, thus justifying its wide use in the empirical literature.

Houthakker and Taylor [1970] focussed on saving fuctions. They started from the proposition that desired wealth, $W^{*}$, is a function of $Y$; e.g.

$$
W_{t}^{*}=f Y_{t}
$$

Assuming then that saving is proportional to the difference between $W^{*}$ and actual wealth, $W$,

$$
S_{t}=s\left(W_{t}^{*}-W_{t-1}\right)
$$

differencing (5) and substituting (4) for $W^{*}$, they obtained an equation of the form,

$$
S_{t}=\beta_{1} \Delta Y_{t}+\beta_{2} S_{t-1}
$$

Equation (6) is Swamy's 'dynamic' saving function equivalent under simple assumptions exposited in Modigliani [1975], to the LCH. With no further assumptions the equivalence in the estimated forms of the LCH and the H-T models can also be demonstrated by starting from (3) and substituting in it $C_{t}$ for its equivalent $Y_{t}-S_{t}$. This gives,

$$
S_{t}=(1-\alpha) Y_{t}-(1-\alpha) Y_{t-1}+(1+r-\delta) S_{t-1}
$$

or

$$
S_{t}=\gamma_{1} \Delta Y_{t}+\gamma_{2} S_{t-1}
$$


where

$$
\gamma_{1}=(1-\alpha) \text { and } \gamma_{2}=(1+r-\delta)
$$

Thus. for a constant $r$, the LCH gives rise to the same estimated form as the H-T model.

The above estimated form may also be derived from the Partial Adjustment (PA) model of consumption, if we equate the desired or equilibrium value of consumption $C_{t}$ to income. Note that this implies a marginal propensity to save equal to zero. Formally, if

$$
C_{t}=Y_{t}
$$

then from

$$
\Delta C_{t}=\zeta\left(Y_{t}-C_{t-1}\right)
$$

it follows that

$$
C_{t}=(1-\zeta) C_{t-1}+\zeta Y_{t}
$$

Subsituting in (11) $C_{t}$ for $Y_{t}-S_{t}$ gives,

$$
S_{t}=(1-\zeta) \Delta Y_{t}+(1-\zeta) S_{t-1}
$$

or in estimated form

$$
S_{t}=\theta_{1} \Delta Y_{t}+\theta_{2} S_{t-1}
$$

where $\theta_{1}=\theta_{2}=(1-\zeta)$. It follows that under our assumptions the PA model gives rise to the same estimated form as the LCH and the H-T models.

A version of this form can also be obtained from the Simple Lag/Habit Persistence and the Adaptive Expectations/Permanent Income models. We can write their estimated equations as

$$
C_{t}=\xi_{1} Y_{t}+\xi_{2} C_{t-1}
$$

see e.g. Ferber (1973). On substituting $C_{t}$ for $Y_{t}-S_{t}$, obtain

$$
S_{t}=\left(1-\xi_{1}\right) Y_{t}-\xi_{2} Y_{t-1}+\xi_{2} S_{t-1}
$$

or

$$
S_{t}=\kappa_{1} Y_{t}-\kappa_{2} Y_{t-1}+\kappa_{2} S_{t-1}
$$

where $\kappa_{1}=\left(1-\xi_{1}\right)$ and $\kappa_{2}=\xi_{2}$. Equation (16) is equivalent to equations (6), (8) and (13), for $\kappa_{1}=-\kappa_{2}$, which can be tested on estimation.

The above estimated form may obviously be derived directly from: a geometrically declining distributed lag-Koyck transformation model of $S_{t}$ on $Y_{t}$ as well as from the identity $S_{t}=S_{t-1}+\Delta S_{t}$, if the assumption $\Delta S_{t}=s\left(\Delta Y_{t}\right)$ is adopted. 
It follows that by focussing on the systematic parts ${ }^{1}$ of a wide range of models-hypotheses of consumption and saving we can rederive the Swamy result and extend it to obtain a general saving function consistent in its estimated form to all these models. ${ }^{2}$

\section{Definitions of variables}

Any generality claims of a saving function must rest on the assumption of a common definition of $S$ and $Y$ by all theories. But such consistency is not met in practice. While for example the $\mathrm{LCH}$ has been associated with the use of private (i.e personal sector plus corporate) income and saving, ${ }^{3}$ the $\mathrm{H}$-T model was normally tested by use of personal sector $S$ and $Y,{ }^{4}$ The latter definition was also used by Brown [1952] in his Habit Persistence model but with no explicit justification. Other theories have been cryptic on this matter. Empirical research often relies upon the official definitions, i.e personal sector $Y$ and $S .^{5}$

To appropriately define $Y$ and $S$ one obviously needs a subject. Here our focus is the household sector. The question we first ask is what disposable income do households have and which part of it do they save. This immediately excludes corporate income from consideration, apart from its part paid-out to the households, i.e. dividends. Similarly the part of life assurance and private pension funds (LAPF) income not disposable to households - the net inflow in life assurance and pension funds (NILP) - is excluded from our definition of household disposable income, see Cuthbertson [1983], Pitelis [1985]. Contributions from the central government however to the households is disposable to the latter and we include it in our definition of Net Peronal Disposable Income (NPDI). This, following conventional national income accounting gives:

NPDI $=(\mathrm{W}+\mathrm{S})+\mathrm{FP}+\mathrm{EC}+\mathrm{CCG}+\mathrm{DIV}+\mathrm{RE}+\mathrm{INT}+\mathrm{SEY}-\mathrm{HTAX}-\mathrm{HCSS}-\mathrm{NILP}$ where

$(\mathrm{W}+\mathrm{S})=$ Wages and Salaries including contributions to LAPF

FP $\quad=$ Pay to the National Forces

EC = Employers Contributions, including contribution to LAPF

CCG = Contributions from the Central Government to Households

DIV $=$ Dividends

RE $\quad=$ Rent

INT $\quad=$ Interest

SEY $\quad=$ Income from Self Employment

HTAX = Taxes to Households

HCSS = Households Contributions to Social Security

and NILP $\quad=$ the Net Inflow in LAPF.

\footnotetext{
${ }^{1}$ Explicit modelling of the error term may give rise to (testable) differences between the models. Apparently equivalent specifications may thus give rise to different results on estimation.

${ }^{2}$ Discrimination may be achieved in case different parameter values are implied by different models and this is tested on estimation. This is not the aim of this paper.

${ }^{3}$ As for example suggested in Ando and Modigliani [1963] and Modigliani [1975].

${ }^{4}$ See for example Taylor [1971] and Taylor and Weiserbs [1972].

${ }^{5}$ This, unlike the LCH excludes corporate retentions from Y and S. Contrary to our treatment to follow, however, it includes the net inflow in Life Assurance and Pension Funds.
} 
As we are interested in disposable income the exclusion of HTAX and HCSS from Y is obvious. As all contributions to LAPF are included in $(\mathrm{W}+\mathrm{S})$ and EC, the exclusion of NILP (contributions to, minus benefits from, LAPF), ensures that only benefits from LAPF paid to households are included in NPDI. The resulting NPDI minus consumer expenditure gives the net saving of the household sector, NPS. ${ }^{6}$ Finally in line with the conventions adopted in the official statistics, we define consumers expenditure to include durable goods. ${ }^{7}$

Our reliance on a net measure of disposable $Y$ and $S$ is consistent with a wide literature in Industrial Organisation which suggests that saving is only made out of corporations or those who control them; e.g. managers and/or a controlling subset of the shareholders and managers, see e.g. Galbraith [1967] and Cowling [1982]. Further, building upon Williamson [1964] it may be suggested that those in control of corporations save and consume within the corporations. Saving e.g. takes the form of corporate retentions and consumption the form of 'managerial' perks, expense accounts etc. Evidence that corporate leaders do consume in this way abounds, see e.g. Aaronovitch and Sawyer [1975]. In the limit if all this group's income takes corporate form, i.e it does not appear in the household sector income accounts, we are left with a much more homogeneous subject to deal with. Namely one that excludes (part of) the saving of those likely to be big savers anyway, the corporate leaders.

Our proposed definitions of $S$ and $Y$, however, overlook the fact that although households have no direct control on NILP and/or CORE, they have ownership claims on them and may view them as their income. ${ }^{8}$ Thus, if they take these funds into account when forming their consumption/saving decisions, NILP and/or CORE should be viewed as if they were personal saving and income. This would take us back to the definitions proposed by the LCH. Whether the latter is the case, however, is something to be tested rather than assumed: which necessitates the appropriate extension of the specification of the saving function to include CORE and NILP.

The extension follows straightforwardly from saving function (6) or (8) in Section 2, and our discussion of the definition of variables in this Section. In line with this latter discussion we can write equations (6) or (8) as,

$$
N P S_{t}=\kappa_{1} \Delta N P D I_{t}+\kappa_{2} N P S_{t-1}
$$

\footnotetext{
${ }^{6}$ Note however that this definition includes the saving of the unincorporated sector (quasi-retentions) which in the official statistics is included in the household sector. Ideally quasi-retentions should be excluded from NPS. Data on quasi-retentions however is not available, se we were precluded from doing so.

${ }^{7}$ The official statistics also include housing in their definition of saving and accordingly housing is included in our definition of NPS. This is also unsatisfactory as it fails to account for households contractual repayments of mortgages. Once more data availability precluded us from adopting the appropriate transformations. Another limitation of the data arises from the lack of any reliable series on capital gains. In our framework the potential effect of the latter on NPS is caputred only partially, through our use of a corporate retained earnings variable, see below.

${ }^{8}$ For CORE this is commonly the case in the empirical literature, which focusses on personal sector $Y$ and $S$. For $N I L P$ this very focus, however, implies that $N I L P$ and net personal income are perfect subsitutes; another common assumption in the empirical literature!
} 
From (17) it follows that

$$
\begin{gathered}
N P S_{t}=\kappa_{1} \Delta N P D I_{t}+\kappa_{2} N P S_{t-1}+\kappa_{3} N I L P_{t} \\
+\kappa_{4} C O R E_{t}
\end{gathered}
$$

where $\kappa_{3}=\kappa_{4}=0$.

Equation (18) can thus be used as an estimated framework to test the above implied restrictions. If they are satisfied this will imply support for the independence hypothesis that households do not take into account NILP and/or CORE when forming their consumption/ saving decisions. If instead the obtained coefficients are equal to minus one this will lend support to the perfect substitution hypothesis, implying that households consider NILP and/or CORE as perfect substitutes for their discretionary saving. An alternative but equivalent way of testing the above hypotheses is to add NILP and CORE both in the right hand side and in the left hand side of equation (17). In this case the dependent variable in (18) will be private saving (PRSA), i.e. NPS + NILP + CORE and accordingly a coefficient of NILP and/or CORE equal to zero will lend support to the perfect substitution view while a coefficient equal to one, to the independence hypothesis. ${ }^{9}$

In the above framework, we address the following questions for our broadly homogeneous household sector. First, what part of their disposable income do they save? Second, to which extent do they take into account income on which they have no direct control, NILP and/or CORE? Further, since the last two represent different types of income, do such (or other) differences in types of income result in different proportions of them being saved?

\section{Data and empirical results}

The data used in this Section cover the 1951-1981 UK period. They have been obtained by adopting the transformations described in Section II, to the official Central Statistical Office (CSO) [1983] data on Personal Sector Disposable Income (PSDI) and Personal Sector Saving (PSS), i.e. PSDI minus Consumers Expenditure. We also used the CSO CORE series. Data on NILP was provided to the author by Mike Sherring of the CSO. All series are defined before providing for depreciation, stock appreciation and additions to tax reserves. Constant 1975 prices were obtained by using the Retail Price Index itself obtained from the CSO. The use of the gross (inclusive of depreciation) measure of CORE is in line with established practice as depreciation allowances are often used for investment and/or tax avoidance purposes, see e.g. Lambrinides [1972], Feldstein [1973], Feldstein and Fane [1973].

For estimation we added an error term to equation (18). Also a constant term, in order to mean correct our series. Methodologically, we adopted a general to specific approach, see Hendry [1983]. We started from our most general version of equation (18) and tested down in order to obtain our preferred equation. Given the presence of the lagged dependent variable

\footnotetext{
${ }^{9}$ The two approaches are exactly equivalent. Still focus on the latter is useful in that this equivalence dispels the myth that the use of aggregate $S$ and $Y$ may somehow be better: see e.g. the discussion between Howrey and Hymans [1978] and Feldstein [1978].
} 
in (18) the estimation by Ordinary Least Squares (OLS) will give rise to biased and inconsistent estimates if the error term is not white noise. To account for this problem we assumed that the error term follows a first order autoregressive scheme of the form $u_{t}=\rho u_{t-1}+e_{t}$, where $e_{t}$ is a serially independent disturbance with zero mean, and attempted to obtain $\hat{\rho}$, by use of a Maximum Likelihood technique. When significant $\hat{\rho}^{\prime} s$ were found Maximum Likelihood estimates were reported. For insignificant $\hat{\rho}^{\prime} s$ the equations were reestimated with OLS and the latter estimates were reported.

Equation (18) was first estimated in its most general form, obtained by relaxing the implied restriction that $\kappa_{1}=\kappa_{2}$ and testing it against the data. The restriction was accepted at the $5 \%$ level of an F test, equation 1.1, Table 2. This result implies a Marginal Propensity to Save (MPS) NPDI equal to zero. Alternatively, that the household sector as a whole save only in contractual forms - CORE and NILP - and when their incomes are changing. This result is well in line with Galbraith's [1967] views, ${ }^{10}$ earlier empirical evidence for which is given in Marglin [1975] for the US and Pearce and Thomas [1981] and Pitelis [1985] for the UK.

In line with our suggestions, in equation 1.2, Table 1, NILP and CORE are added to both the left hand and to the right hand side of 1.2. Private Saving (PRSA) is the new dependent variable. 1.2 exactly reproduces the results of 1.1 as expected and gives rise to a spurious increase in the explanatory power of the equation. In 1.2. both the coefficients of CORE and NILP are statistically equal to one. When restricted to be equal to each other, equation 1.3 resulted. As both CORE and NILP are contractual in nature, the resulting variable was named contractual saving, COSA. The restriction was not rejected and the explanatory power of the equation was increased. It follows that equation 1.3 is our preferred one. On its coefficients ' $t$ ' tests were performed and showed the existence of zero substitution between NILP and CORE on the one hand and NPS on the other: a result broadly in line with the existing evidence. ${ }^{11}$ An alternative way to test the Galbraith hypothesis of a zero MPS net personal disposable income, is to include NPDI as an additional explanatory variable in 1.3. This gives rise to 1.4 which as expected confirmed our previous results which lent support to the Galbraith hypothesis.

It is often suggested that different types of income are saved in different proportions. Our results support this view to the extent that CORE, NILP and NPDI are different types of income, but not for different types of NPDI; as we failed to find any saving at all out of the level of the latter. Explicit testing of this finding can be made if conventional types of incomes are derived from NPDI, e.g. Net Wage Income (NWI) and Net Property Income (NII), as in the classic Klein and Goldberger [1955] and Klein et al [1961] studies. Thus we can define,

$$
\mathrm{NWI}=(\mathrm{W}+\mathrm{S})+\mathrm{FP}+\mathrm{EC}+\mathrm{CCG}-\mathrm{WTAX}-\mathrm{WCSS}-\mathrm{NILP}
$$

where $(\mathrm{W}+\mathrm{S}), \mathrm{FP}, \mathrm{EC}, \mathrm{NILP}$, and CCG are as in Section II

WTAX = Taxes to Wage Income and

WCSS $=$ Social Security Contributions out of Wage Income.

${ }^{10}$ Based on the idea that modern societies are characterised by producers' rather than consumers' sovereignty. As a result advertising and other selling activities of the corporate sector will induce high consumption propensities to the household sector. Duesenberry's [1967] 'demonstration effect' is also a case in point.

${ }^{11}$ For a survey of the literature on pension funds, see Kessler et al [1981]. For surveys and evidence on pension funds and CORE, see Pitelis [1985, 1986] respectively. 


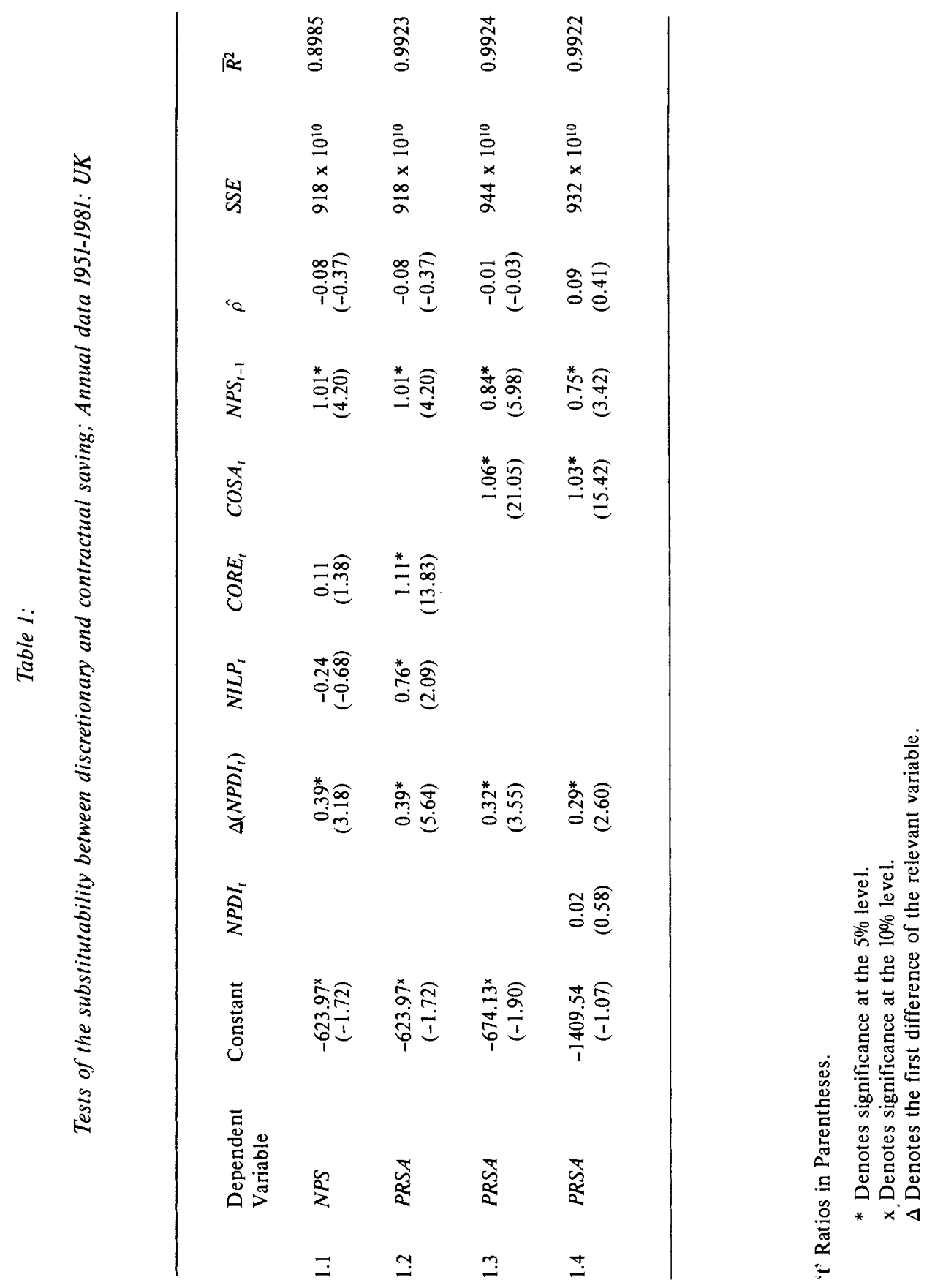




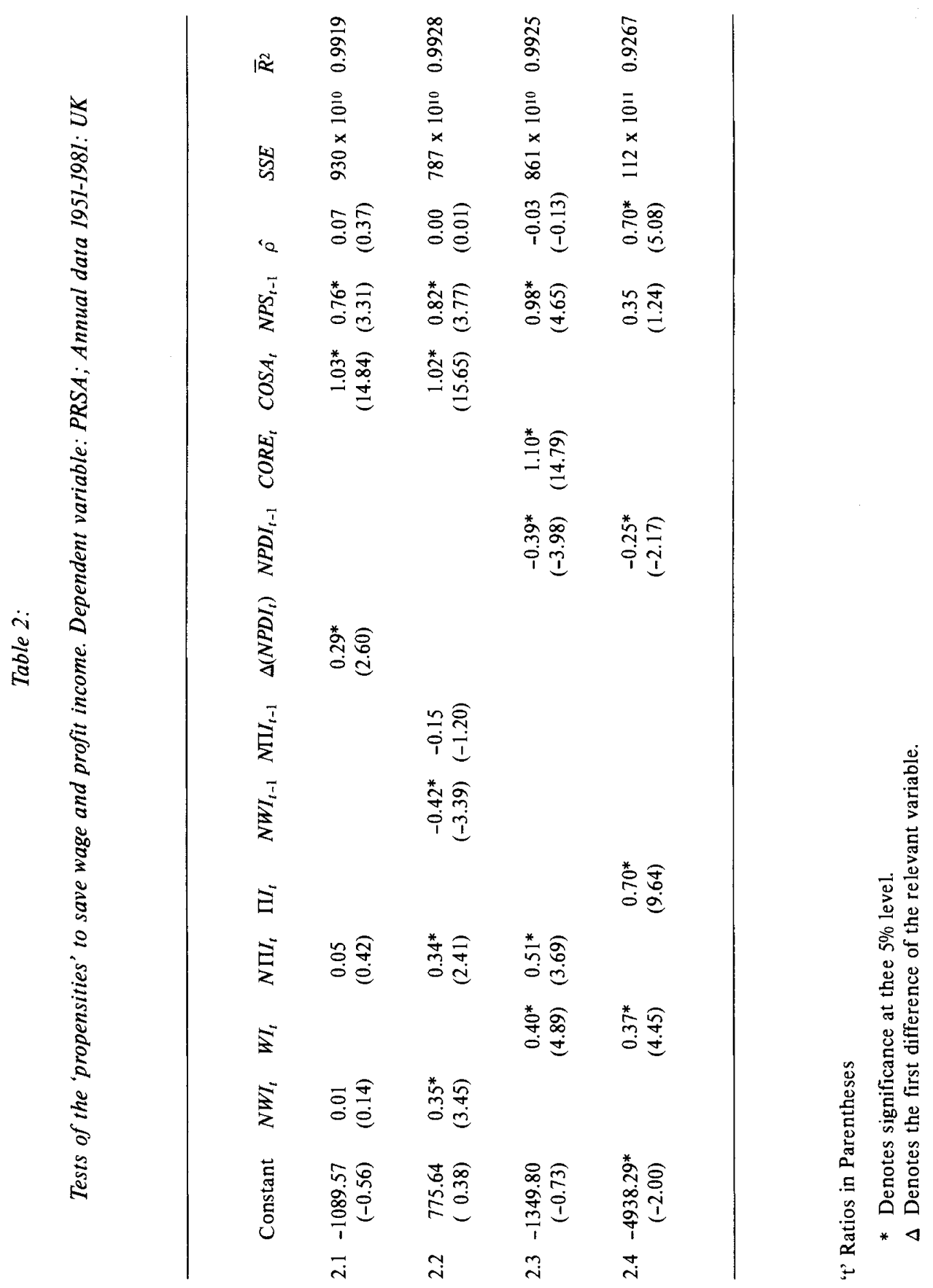




$$
\mathrm{N} \Pi \mathrm{I}=\mathrm{DIV}+\mathrm{RE}+\mathrm{INT}+\mathrm{SEY}-\mathrm{\Pi TAX}-\Pi \mathrm{ICSS}
$$

where DIV, RE, INT and SEY are as in Section II,

$\operatorname{IITAX}=$ Taxes to Property Income, and

ICSS $=$ Contributions to Social Security out of Property Income.

The justifications for the distinctions described above is by now common ground in the literature on differential propensities, see e.g. Pitelis [1986a] for a recent survey, to require further discussion here. Instead the results of adopting these distinctions in 1.3 are reported in 2.1, Table 2. As expected zero MPS for both NWI and NחI are obtained. Allowing for saving out of the change in NWI and NחI involves including their lagged values in the estimated equation, as in 2.2. $\triangle(N P D I)$ in 2.1 is now redundant as its impact is captured via the coefficients of NWI, NII and their lagged values, in 2.2. Positive and significant savings are obtained for NWI and NII in 2.2. Most important is that we can go back from 2.2. to its restricted version 1.2. and see that by performing an $\mathrm{F}$ test, all restictions implicit in 1.3 are supported at the 5\% level: implying equal proportions saved out of $\Delta(N W I)$ and $\Delta(N \Pi I)$.

As seen, the official CSO data include NILP in wage income under the headings (W+S) and EC. If this procedure is adopted here then aggregate wage income (WI) can be written as NWI + NILP and the proportion of WI saved with be given in 2.3. Again an $F$ test indicated that the coefficients of WI and NII are insignificantly different from each other, in line with most recent studies on this issue, which report similar findings by use of the official (personal sector) definitions of $\mathrm{S}$ and $\mathrm{Y} .{ }^{12}$

Adopting the same procedure for CORE and including it in property income will give aggregate property income as $\Pi \mathrm{I}=\mathrm{N} I \mathrm{I}+\mathrm{CORE}$. Thus, 2.4 will test the 'Kaldorian' saving function as WI and $\Pi I$ were the definitions of wage and property income proposed in Kaldor $[1960,1966]$. Note that other studies which fail to include CORE in property income also fail to test the Kaldorian hypothesis consistently. Our results support Kaldor's suggestion that III will be saved in a higher proportion than WI. An $F$ test rejected the hypothesis that in 2.4 the coefficients of $\Pi I$ and WI are equal. Important however is that contrary to conventional wisdom the obtained coefficients in 2.4 do not refer to the 'propensities' of the respective owners of wage and property income. Rather they refer to an amalgam of the latters' contractual savings and their savings out of their changing income shares. Recall that actual propensities were found to be zero.

\footnotetext{
${ }^{12}$ See Pitelis [1986a] for a survey of these studies and further evidence. It should be noted that by bringing together in a common framework the role of NILP, CORE and wage and profit income on saving, the present study provides an integration of previous work in Pitelis [1985, 1986, 1986a]. More importantly however, it departs from these studies in that by focussing explicitly on the household sector only, it makes explicit the need for developing a separate theory for the determination of corporate saving, NILP and CORE. In this sense it provides a criticism to the orthodox theories of consumption/saving which by focussing on aggregate income and saving imply that households rather than corporations are in control of corporate saving decisions.
} 


\section{Concluding remarks}

We have seen that focussing in the systematic parts of the estimated forms of many consumption/saving functions we reproduced the Swamy result and extended it to encompass most models-hypotheses proposed to-date. We suggested net disposable income and saving as the appropriate definitions to be used for the specification of the obtained general saving function. This latter specification should then be extended to account for the potential impact of households' ownership claims on their contractual saving, on their consumption/saving behaviour: i.e. the substitutability of saving.

Our results supported the ideas that the household sector does not save out of their current discretionary income. They only appear to save out of their changing incomes, and in the form of contractual saving such as NILP and CORE. Households do not appear to take account of the latter however, when drawing their consumption/saving plans, 'preferring' to rely on what do they actually control; their net personal disposable income. What are conventionally termed 'propensities' may represent in practice an amalgam of transient and contractual savings on the part of (different types of) households. Providing this is kept in mind, our results gave support to much of the conventional wisdom; e.g. equal 'propensities' to save personal sector wage and property income, the 'Kaldorian' hypothesis, etc.

Our results were robust to a wide range of explanatory variables such as the rates of interest and inflation. These results are not reported to economise space but are available from the author on request. Serious econometric problems were not evident. In particular neither first order autocorrelation nor multicollinearity appeared to exist as our tests and the high ' $t$ ' statistics respectively, indicated. The CORE and NILP variables were assumed exogenous; i.e. determined outside the control of the household sector. Recalling our discussion in Section 2, this hypothesis appears plausible. Private pension funds are largely compulsory, while it is often suggested that small scale shareholders have little control over corporate retentions, see Wood (1975). In formal terms, writing

$$
\operatorname{COS} A_{t}=c(.)
$$

where $c$ is a functional form and (.) the set of explanatory variables that affects $\operatorname{COSA}$, then if as suggested NPS does not enter the set (.), our estimated equations and (19) form a recursive model capable of being estimated with OLS, and without the problem of Simultaneous Equations Bias. All in all, the above suggest that both our innovative and conventional results and suggestions are of some value.

\section{REFERENCES}

AARONOVITCH, S. and SAWYER, M. [1975]: Big Business: Theoretical and Empirical Aspects of Concentration and Mergers in the UK. Macmillan, London.

ANDO, A. and MODIGLIANI, F. [1963]: "The life cycle hypothesis of savings: Aggregate implications and tests", American Economic Review, (March 1963), 53, 55-84.

BROWN [1952]: "Habit persistence, and lags in consumer behaviour", Econometrica, (July 1952), 355-371. 
COWLING, K. [1982]: Monopoly Capitalism. Macmillan, London.

CUTHBERTSON, K. [1983]: "The measurement and behaviour of the UK saving ratio in the 1970s", National Institute Economic Review, (February 1983), 75-84.

DAVIDSON, S., HENDRY, D., SRBA, F., and YEO, S. [1978]: "Econometric modelling of the aggregate time-series relationship between consumers' expenditure and income in the United Kingdom", The Economic Journal, (December 1978), 661-692.

DAVIS, E.P. [1984]: "The comsumption function in macroeconomic models: A comparative study", Applied Economics, (December 1984), 799-838.

DUESENBERRY, J.S. [1967]: Income, Saving and the Theory of Consumer Behaviour. Oxford University Press, New York.

FELDSTEIN, M. [1973]: "Tax incentives, corporate savings, and capital accumulation in the United States", Journal of Public Economics, 2 (1973), 159-171.

FELDSTEIN, M. [1978]: “Do private pensions increase national savings?", Journal of Public Economics, 10 (1978), 277-293.

FELDSTEIN, M. and FANE, G. [1973]: "Taxes, corporate dividend policy and personal savings. The British postwar experience", Review of Economics and Statistics, 4 (November 1973), 399-411.

FERBER, R. [1973]: “Consumer Economics: A survey”, Journal of Economic Literature, (December 1973), 1303-1342.

FRIEDMAN, M. [1957]: A Theory of the Consumption Function. Princeton University Press, Princeton.

GALBRAITH, J.K [1967]: The New Industrial State. Penguin Books, London.

HENDRY, D.F. [1983]: "Econometric modelling: The 'consumption function' in retrospect", Scottish Journal of Political Economy, (November 1983), 193-220.

HOUTHAKKER, H.S. and TAYLOR, L.D. [1970]: Consumer Demand in the United States 1929-1970: Analyses and Projections. Harvard University Press.

HOWREY, E.P. and HYMANS, S.H. [1978]: "The measurement and determination of loanable-funds saving”, Brookings Papers on Economic Activity, 3, 655-85.

KALDOR, N. [1960]: Essays on Value and Distribution. Duckworth Ltd., London.

KALDOR, N. [1966]: "Marginal productivity and macro-economic theories of distribution", Review of Economic Studies, (October 1966), 301-311.

KESSLER, D., MASSON, A. and STRAUSS-KAHN, D. [1981]: "Social security and saving: A tentative survey", The Geneva Papers on Risk and Insurance, 18 (January 1981), 3-50.

KLEIN, L.R. and GOLDBERGER, A. [1955]: An Econometric Model of the US. North Holland Publishing Company, Amsterdam.

KLEIN, L.R., BALL, R.J., HAZLEWOOD, A. and VANDOME, P. [1961]: An Econometric Model of the $U K$. Oxford, Blackwell.

LAMBRINIDES, M. [1972]: "Saving, distribution and social choice: A study of the relationship between personal and organizational saving". Unpublished PhD Thesis. Harvard University.

MARGLIN, S. [1975]: "What do bosses do? The origins and functions of hierarchy in capitalist production", Part II, Review of Radical Political Economics, (Winter 1975), 20-37.

MODIGLIANI,F. [1970]: "The life cycle hypothesis of saving and inter country differences in the savings ratio", in W. Eltis et al. (Eds), Induction Growth andTrade, Essays in Honour of Sir Roy Harrod, Oxford University Press.

MODIGLIANI, F. [1975]: "The life cycle hypothesis of saving twenty years later" in Parkin, M. and Nobay, A.(Eds), Contemporary Issues in Economics, Proceedings of the Conference of the Association of University Teachers of Economics, Warwick, 1973.

PEARCE, I.F. and THOMAS, J.H. [1981]: "The personal savings paradox", University of Southampton, Discussion Paper No. 8025. 
PITELIS, C.N.[1985]: "The effects of life assurance and pension funds on other savings: The postwar UK experience", Bulletin of Economic Research, 37.

PITELIS, C.N. [1986]: "Corporate retained earning and personal sector saving: A test of the life cycle hypothesis of saving", Applied Economics, forthcoming.

PITELIS, C.N. [1986a]: "Corporate retained earnings and the 'Kaldorian' hypothesis of saving”, University of Nottingham Discussion Paper in Industrial Economics, No. 1986, 10.

SPIRO, A. [1962]: "Wealth and the consumption function", Journal of Political Economy, August, 339-354.

SWAMY, S. [1968]: “A dynamic personal savings function and its long run implications”, The Review of Economics and Statistics, Vol. XLIX, February, 111-116.

TAYLOR, L.D. [1971]: "Saving out of different types of income”, Brookings Papers of Economic Activity, 2, 383-407.

TAYLOR, L. and WEISERBS, D. [1972]: “Advertising and the aggregate consumption function", American Economic Review, September.

WALLIS, K. [1979]: Topics in Applied Econometrics, Basil Blackwell, Oxford.

WILlIAMSON, O.E. [1964]: The Economics of Discretionary Behaviour, Prentice Hall.

WOOD, A. [1975]: A Theory of Profits, Cambridge University Press, Cambridge. 